$\begin{array}{ll} & \text { Etnográfica } \\ \text { etnográfica } & \text { Revista do Centro em Rede de Investigação em }\end{array}$

Antropologia

vol. $16(2) \mid 2012$

Vol. $16(2)$

\title{
Manuela Ivone Cunha e Jean-Yves Durand (orgs.), Razões de Saúde: Poder e Administração do Corpo; Vacinas, Alimentos e Medicamentos
}

\section{Catarina Fróis}

\section{(2) OpenEdition}

\section{Journals}

\section{Edição electrónica}

URL: https://journals.openedition.org/etnografica/1571

DOI: 10.4000/etnografica.1571

ISSN: 2182-2891

\section{Editora}

Centro em Rede de Investigação em Antropologia

Edição impressa

Data de publição: 1 junho 2012

Paginação: 421-423

ISSN: 0873-6561

\section{Refêrencia eletrónica}

Catarina Fróis, «Manuela Ivone Cunha e Jean-Yves Durand (orgs.), Razões de Saúde: Poder e

Administração do Corpo; Vacinas, Alimentos e Medicamentos», Etnográfica [Online], vol. 16 (2) | 2012, posto online no dia 26 junho 2012, consultado o 12 fevereiro 2022. URL: http://

journals.openedition.org/etnografica/1571 ; DOI: https://doi.org/10.4000/etnografica.1571

\section{(c) (7) \&)}

Etnográfica is licensed under a Creative Commons Attribution-NonCommercial 4.0 International License. 
Manuela Ivone Cunha

e Jean-Yves Durand (orgs.)

RAZÕES DE SAÚDE:

PODER E ADMINISTRAÇÃO

DO CORPO; VACINAS, ALIMENTOS

E MEDICAMENTOS

Lisboa, Fim de Século, 2011 ,

230 páginas,

ISBN: 9789727542826.

"Tenho aprendido muito com o povo. Nele, as coisas que dão à vida a inesgotável grandeza não foram ainda violadas nem empobrecidas. O instinto do povo guarda-lhes o mistério e a seiva. Ainda hoje, na consulta, ao insistir com um aldeão para que me descrevesse o seu mal, ele, por fim, disse-me:

- É a natureza comida.

A natureza - o sexo. Deem-me tratados onde se atinja esta sabedoria e esta serena humildade" (Fernando Namora, Domingo à Tarde).

Razões de Saúde: Poder e Administração do Corpo; Vacinas, Alimentos e Medicamentos é uma coletânea organizada por Manuela Ivone Cunha e Jean-Yves Durand, e reúne um conjunto de ensaios centrados em dois grandes domínios: o da perceção e consciência do sujeito e da autonomia das suas decisões em relação ao seu próprio corpo e, para além disso, o do modo como essas mesmas decisões revelam e traduzem, em determinados contextos, uma agencialidade política, uma consciência cívica que contraria o status quo dominante.

Devem ser salientadas, à partida, as mais-valias que esta obra apresenta: é um estudo inovador sobre a gestão do corpo na área da medicina e da terapêutica, convencionais ou "alternativas"; a abordagem etnográfica é centrada na sua grande maioria no contexto português, permitindo assim contrastar com obra e teoria produzida sobretudo na academia anglo-saxónica; por fim, proporciona um encontro de perspetivas multidisciplinares que partilham quer o tema, quer os saberes e as metodologias que lhe são específicas. Podemos, neste último ponto, afirmar que a multidisciplinaridade é hoje uma quase obrigatória presença em volumes coletivos, no sentido em que se tornou prática corrente. Ora, neste caso, tem-se claramente a perceção de que os organizadores deste livro tiveram a consciência de que os espaços em que se moviam reclamavam uma abordagem holística, uma vez que são, já de si, lugares de confluência de diferentes profissionais.

Consideremos, a título de exemplo, como lugar de observação um centro de saúde para onde se dirigem diariamente dezenas de pessoas com o propósito de consultar um médico ou requerer serviços de enfermagem. Esse é, por excelência, um lugar onde se encontram médicos, enfermeiros, psicólogos, assistentes sociais e também, neste caso, o antropólogo, o etnógrafo. Aqui, não é apenas a ciência que impõe um 
olhar multidisciplinar, é o próprio objeto de estudo que exige que esse olhar esteja em permanente diálogo com diferentes disciplinas. Esta ideia é especialmente pertinente se tivermos em conta que não é somente o etnógrafo que faz um esforço de compreensão transversal ao objeto, são os próprios utentes dos serviços médicos que a dado momento absorvem, incorporam e racionalizam um discurso médico-científico, formulando um autodiagnóstico, uma compreensão da sua "doença" e do melhor modo de a tratar, adaptando e até corrigindo a terapêutica que lhes é prescrita.

Uma última nota a propósito dos espaços de análise desta obra e da sua relevância para a produção científica desta área: a ênfase no contexto português, a que corresponde grande parte dos ensaios aqui apresentados. Seria demasiado óbvio constatarmos a priori que temas como a vacinação ou a autonomia do sujeito face à doença diferem grandemente em Portugal ou nos Estados Unidos da América. Se, no primeiro, existe um Plano Nacional de Vacinação "recomendado", mas que se assume de facto como "obrigatório", no segundo cabe a cada pessoa decidir qual a opção que segue face a esta questão. Porém, é só mediante esta observação cuidada do contexto português que nos é permitido discutir com propriedade teorias resultantes de investigação produzidas noutros contextos. Ao inseri-las num determinado locus histórico, cultural, social e económico, estamos de imediato a demonstrar que a sua aplicação indiferenciada tende a ser incongruente e até mesmo desajustada.

A obra está dividida em duas partes. Numa primeira, temos acesso a uma diversidade de ensaios que giram em torno do conhecimento médico-científico, num contexto de lógica política e interação entre médico e paciente, com os textos de Sylvie Fainzang sobre terapêutica, de Cristiana Bastos focando a sida, e de Emily Martin sobre o sono; noutra vertente, surge ainda a automedicação e a saúde mental no campo das toxicodependências e da anorexia, com os textos de Luís Fernandes e de Ana Cristina Martins. Estes dois últimos textos diferenciam-se dos restantes na medida em que o consumo de drogas psicoativas, para além da manifestação de um comportamento autodestrutivo, é um dos exemplos paradigmáticos do modo como a ingestão de drogas é, por si mesma, uma autoterapia, a identificação de um "mal" - entre outras características, a doença da adicção define-se pelos comportamentos obsessivos e compulsivos - e a escolha de um "remédio", neste caso ilegal e que por sua vez desencadeia todo um processo terapêutico paralelo, através da medicina convencional. ${ }^{1}$

A segunda parte do livro é totalmente consagrada ao tema da vacinação, com textos de Mónica Saavedra, Anne Marie Mourin, Manuela Ivone Cunha e Jean-Yves Durand, e apresenta exemplos do modo como esta prática médica é, por um lado, largamente aceite pela população e, por outro lado, questionada e até mesmo rejeitada em prol de diferentes tipos de conduta e de gestão do corpo, como por exemplo através da alimentação macrobiótica, como reflete Virgínia Calado.

É importante termos em conta que, ao falarmos sobre vacinação, neste livro estamos sobretudo a considerar a vacinação de crianças. Nesse sentido, os interlocutores privilegiados foram pais com crianças menores, que se confrontam com essa questão. Se é sobretudo nestas idades que a vacinação assume um papel mais presente

1 Gregory Bateson, numa obra de 1972, Steps to an Echology of Mind (University of Chicago Press) reconhecia precisamente este paradoxo: o alcoólico bebe como resposta à sua doença, mas, quando é tratado do alcoolismo, não estará a medicina a trazê-lo novamente para a condição de doente? 
ao nível da preocupação dos prestadores de cuidados de saúde, é também nesta fase que os pais assumem consciente ou inconscientemente uma tomada de posição. O texto de Maria José Casa-Nova ilustra bem esta ambiguidade no contexto de famílias ciganas, em que existem crianças que não são vacinadas por "descuido" ou "desinteresse" da família (ideias manifestadas por alguns interlocutores da autora), mas, para outras, é o inverso que é privilegiado: vacinar é a expressão do cuidado, da proteção, mesmo quando implica a compra de vacinas que não são comparticipadas pelo Estado mas que se considera serem uma prevenção, um cuidado extra que se tem para com as crianças.

A questão da vacinação demonstra a sua complexidade - e talvez sejam os textos de Virgínia Calado e de Manuela Ivone Cunha e Jean-Yves Durand os que melhor a explicitam - no âmbito da recusa da vacinação enquanto expressão de agencialidade política. Tal acontece no sentido em que são aqueles que têm um maior conhecimento sobre os propósitos e efeitos da vacinação que a questionam e põem em causa todo o sistema político hegemónico no qual esse

Patricia de Santana Pinho

MAMA AFRICA:

REINVENTING BLACKNESS IN BAHIA

Durham, NC: Duke University Press,

2010, 280 pages,

ISBN: 9780822346463.

In Mama Africa, Brazilian social scientist Patricia de Santana Pinho details the influence that "Africa" has on conceptions of blackness in Bahia, the northeastern plano está inserido. Vacinar não representa então um cuidado acrescido, mas antes um risco desnecessário, e a autoridade médica é desafiada nos seus preceitos e convicções. Não vacinar, para além de uma escolha, torna-se um ato de resistência rara no contexto português. Assim, não estamos a falar de uma lógica economicista, como sucede noutros países, mas antes na consciência de si próprio e da gestão do corpo, na saúde e na doença. Ora, estamos antes de mais perante um tema que provoca e espoleta toda uma série de inquietações, não só em termos teóricos e académicos, mas também ao nível da sociedade civil, da comunidade médica e dos decisores políticos. Neste sentido, esta é uma obra que tem a potencialidade de catapultar essa discussão e contribuir para um conhecimento informado que não se confine nem à coleta de informação ad hoc e acrítica, nem à partilha de um modelo que, na prática, se desconhece.

\section{Catarina Frois}

Centro em Rede de Investigação em Antropologia, ISCTE - Instituto Universitário de Lisboa, Portugal catarina.frois@netcabo.pt

Brazilian state with the country's largest Afro-descendent population and a black culture known for its vibrancy. The receptiveness of Afro-Bahians to black cultural influences from abroad, coupled with the desire of outsiders to project African "tradition" and "purity" onto the state, has defined its place within the diasporic "black Atlantic". As such, Afro culture in Bahia influences, and is influenced by, the other nodes of the African diaspora in the New World (namely the USA, Cuba, and 